\title{
Effects of partial and continuous reinforcement on acquisition and extinction in classical appetitive conditioning*
}

\author{
C. X. POULOS $†$ and I. GORMEZANO \\ University of Iowa, Iowa City, Iowa 52242
}

\begin{abstract}
A study was conducted to determine the effects of a continuous and random $50 \%$ schedule of reinforcement on classical appetitive conditioning and extinction of the rabbit's jaw movement response. It was found that partial reinforcement led to a slower rate of acquisition, lower asymptotic level, and slower rate of extinction. The findings were discussed with regard to incentive theory and stimulus aftereffects accounts of partial reinforcement effects in instrumental reward conditioning.
\end{abstract}

The only systematic investigation of the effects of partial and continuous reinforcement on classical appetitive conditioning in infrahumans are those reported by Wagner, Siegel, Thomas, and Ellison (1964) and Holmes and Gormezano (1970). Wagner et al examined the salivary response to food in dogs, and Holmes and Gormezano examined the jaw movement response (a component of the swallow reflex) to a squirt of water to the oral cavity of rabbits. Both investigations revealed a higher final level of performance for continuous than for partial reinforcement and a minimal partial reinforcement extinction effect (PREE) as revealed by a significant Groups by Trials interaction.

In the Wagner et al study, the first trial of extinction was the only acquisition data reported, whereas the Holmes and Gormezano study did not unequivocally demonstrate that the acquisition differences obtained under partial and continuous reinforcement were asymptotic. Furthermore, the finding by Poulos, Sheafor, and Gormezano (1971) that the extent of single alternation of classical appetitive jaw movement CRs under a single-alternation schedule was a monotonic increasing function of US magnitude suggested that the obtaining of only a marginal PREE by Holmes and Gormezano may have been due to the small US magnitude (1-cc squirt of water) employed. Such an inference arises from the assumption that stimulus aftereffects accounts (cf. Capaldi, 1967; Sheffield, 1949) would expect variables affecting single-alternation behavior to also affect the PREE. Accordingly, the present study was designed to assess the acquisition and extinction effects of partial and continuous reinforcement under more extended acquisition training and larger US magnitude than previously employed.

*This research was supported by Grant GB-45131 from the National Science Foundation. Requests for reprints should be sent to I. Gormezano, Department of Psychology, University of Iowa, Iowa City, Iowa $\mathbf{5 2 2 4 2}$

+ Now at the Department of Psychology, University of Toronto, Toronto, Ontario, Canada.

\section{METHOD}

\section{Subjects}

The Ss were 24 male and female albino rabbits 80-100 days old, and each weighed about $2.2 \mathrm{~kg}$ on arrival.

\section{Apparatus}

The apparatus and recording technique has been described by Mitchell and Gormezano (1970), who detail departures from earlier procedures (Smith, DiLollo, \& Gormezano, 1966). The US was a pulsed delivery of $13 \mathrm{cc}$ of distilled water into the rabbit's oral cavity, with each pulse consisting of a 1-cc squirt delivered over a .3-sec interval. The interval between each successive 1-cc squirt was $.45 \mathrm{sec}$ and provided an almost uninterrupted stream of water. Thus, the total duration of the $13-\mathrm{cc}$ US was $9.3 \mathrm{sec}$. The CS was an $80-\mathrm{dB} 1,000-\mathrm{Hz}$ tone which was $8 \mathrm{~dB}$ above a continuous white noise. The CS-US interval was $500 \mathrm{msec}$ with the CS terminating at the point of US onset.

\section{Procedure}

The Ss were anesthesized, a polyethylene cannula was permanently inserted through a fistula in their left cheek, and a wound clip was applied to the lower jaw. After a 48-h recovery period, the Ss were restricted to $104 \mathrm{cc}$ of water per day for the duration of the experiment. Prior to the availability of water on the fourth day, the Ss were adapted to the apparatus and their base level of jaw movements recorded at times corresponding to the CR observation interval of subsequent acquisition and extinction sessions. Thirty-six days of acquisition training began on the following day with Ss randomly assigned to a random $50 \%$ and $100 \%$ reinforcement condition. All Ss then received 12 days of extinction training.

In acquisition and extinction, all Ss received eight trials per day at random intertrial intervals of 170,210 , and $250 \mathrm{sec}$ (mean of $210 \mathrm{sec}$ ). A CR was defined as a jaw movement of at least $.25 \mathrm{~mm}$ from baseline during the $25-$ to $525-\mathrm{msec}$ interval following CS onset. Under the present volume of US delivery, there was some differential ability among Ss to totally consume the US. Accordingly, individual records of water loss were obtained and each $S$ was individually supplemented to maintain its 104-cc per day regime. The average amount of water loss per session was approximately $10 \%$.

\section{RESULTS}

Figure 1 presents the mean base rate of responding in adaptation and the mean percentage of CRs over 3-day blocks in acquisition and 2-day blocks in extinction. 


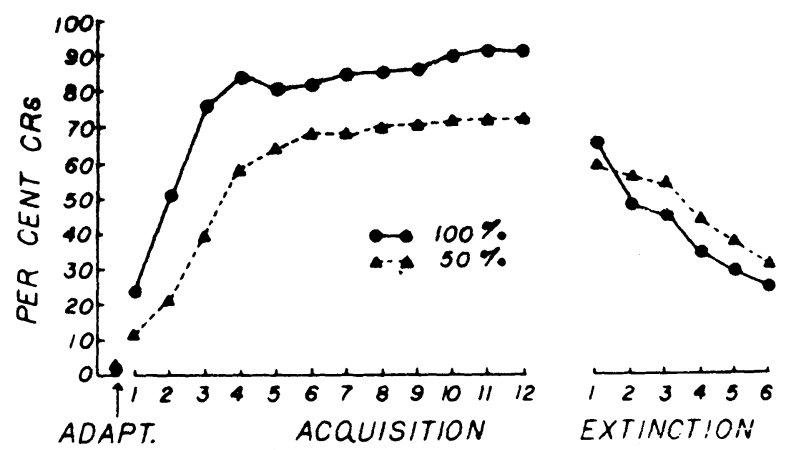

Fig. 1. The mean base rate of responding in adaptation and the mean percentage of CRs plotted in 3-day blocks in acquisition and 2-day blocks in extinction.

Examination of the figure reveals a base rate of less than $2 \%$ in adaptation and a differential rate of increase in percentage CRs over acquisition to essentially asymptotic levels of responding of $73 \%$ and $90 \%$ for the $50 \%$ and $100 \%$ groups, respectively. An analysis of variance performed on the percentage CRs in 3-day acquisition blocks yield significant effects of groups $(\mathrm{F}=$ $16.25, \mathrm{df}=1 / 264, \mathrm{p}<.01)$, blocks $(\mathrm{F}=19.79$, df $=$ $11 / 264, \mathrm{p}<.01)$, and Groups by Blocks $(\mathrm{F}=2.30, \mathrm{df}=$ $11 / 264, p<.01)$. Furthermore, a determination of the number of trials to the first CR for the $50 \%$ and $100 \%$ groups yielded significantly different means of 25.17 and 13.33 , respectively $(\mathrm{t}=2.37, \mathrm{df}=22, \mathrm{p}<.05)$.

Examination of the extinction performance portrayed in Fig. 1 reveals that the percentage CRs of the $100 \%$ group dropped rapidly in the first extinction block to a level slightly above the $50 \%$ group, followed by a crossover in the second block to a level of responding that remained below the $50 \%$ group throughout all subsequent blocks of extinction. An analysis of variance on the percentage $\mathrm{CRs}$, in 2-day blocks, revealed significant effects of blocks $(F=3.23$, df $=5 / 132$, $\mathrm{p}<.01)$ and Groups by Blocks $(\mathrm{F}=2.37, \mathrm{df}=5 / 132$, $\mathrm{p}<.05)$, but no significant groups effect $(\mathrm{F}<1.0)$.

\section{DISCUSSION}

The observation in the present study of a slower rate of acquisition and lower asymptotic level of performance under partial than under continuous reinforcement represents fairly strong documentation of the detrimental effects of nonreinforcement on the acquisition of classical appetitive CRs. In particular, any simple strength model that does not recognize any unique detrimental effect of nonreinforcement (e.g., Hull, 1952) would expect the larger US magnitude and the more extended acquisition training employed (relative to the Holmes and Gormezano study) to have eventually led the partial reinforcement group to equal asymptotic levels of performance.
On the other hand, the observed acquisition partial reinforcement effects are consistent with any of the variety of learning formulations which assume response strength to be increased by reinforcement and decreased by nonreinforcement (e.g., Bush \& Mosteller, 1955; Estes, 1950). Furthermore, the finding of a lower asymptote under partial reinforcement bears upon the account given by incentive theory, and its extension through the concept of frustration (Amsel, 1958; Spence, 1960), of partial reinforcement effects in instrumental reward conditioning. Since the argument has been developed elsewhere (Holmes \& Gormezano, 1970), it will not be treated here except to indicate that the present finding complicates the theory's prediction of performance asymptotes under partial and continuous reinforcement.

Although the PREE defined by a groups effect did not materialize, a PREE was revealed by a Groups by Blocks interaction that, unlike those obtained in the previous classical appetitive conditioning studies, was produced by a crossover during extinction by the continuous reinforcement group. That is, the continuous group performed at a higher level than the partial group during the initial extinction block and then dropped to a lower level of performance during the subsequent extinction blocks. Thus, the interaction cannot be attributed merely to the differences in final level of acquisition. This more convincing demonstration of a PREE with the employment of a large US magnitude and the earlier finding that single alternation of classical appetitive CRs was a function of US magnitude (Poulos, Sheafor, \& Gormezano, 1971) suggests that the stimulus aftereffects accounts (cf. Capaldi, 1967; Sheffield, 1949) of the partial reinforcement variable in instrumental appetitive conditioning may be applicable to classical appetitive conditioning.

\section{REFERENCES}

Amsel, A. The role of frustrative non-reward in non-continuous reward situations. Psychological Bulletin, 1958, 55, 102-119.

Bush, R. R., \& Mosteller, F. Stochastic models for learning. New York: Wiley, 1955.

Capaldi, E. J. A sequential hypothesis of instrumental learning. In $\mathrm{K}, \mathrm{W}$. Spence and J. T. Spence (Eds.), The psychology of learning and motivation. Vol. I. New York: Academic Press, 1967. Pp. 67-156.

Estes, W. K. Toward a statistical theory of learning. Psychological Review, 1950, 57, 94-107.

Holmes, J. D., \& Gormezano, I. Classical appetitive conditioning of the rabbit's jaw movement response under partial and continuous reinforcement schedules. Learning \& Motivation, $1970,1,110-120$.

Hull, C. L. A behavior system. New Haven, Conn: Yale University Press, 1952.

Mitchell, D. S., \& Gormezano, I. Effects of water deprivation on classical appetitive conditioning of the rabbit's jaw movement response. Learning \& Motivation, 1970, 1, 199-206.

Poulos, C. X., Sheafor, P. J., \& Gormezano, I. Classical appetitive conditioning of the rabbit's (Oryctolagus cumiculus) jaw-movement response with a single-alternation schedule. Journal of Com parative \& Physiological Psychology, 1971, 75, 231-238.

Sheffield, V. F. Extinction as a function of partial reinforcement and distribution of practice. Journal of Experimental Psychology, 1949, 39, 511-526.

Smith, M. C., DiLollo, V., \& Gormezano, I. Conditioned jaw movement in the rabbit. Journal of Comparative \& Physiological Psychology, 1966, 62, 479-483.

Spence, K. W. Behavior theory and learning. Englewood Cliffs, N.J: Prentice-Hall, 1960.

Wagner, A. R., Siegel, S., Thomas, E., \& Ellison, G. D. Reinforcement history and the extinction of a conditioned salivary response. Journal of Comparative \& Physiological Psychology, 1964, 58, 354-358.

(R eceived for publication June 7, 1974.) 